\title{
You Don't Know Me But Can I Be Your Friend? Accepting Strangers as Friends in Facebook
}

\author{
Serena Leow, Zuoming Wang \\ Department of Communication Studies, University of North Texas, Denton, TX, USA \\ Email: wangz@unt.edu
}

How to cite this paper: Leow, S. and Wang, Z.M. (2019) You Don't Know Me But Can I Be Your Friend? Accepting Strangers as Friends in Facebook. Social Networking, 8, 52-73.

https://doi.org/10.4236/sn.2019.81004

Received: December 7, 2018

Accepted: December 26, 2018

Published: December 29, 2018

Copyright (๑) 2019 by authors and Scientific Research Publishing Inc. This work is licensed under the Creative Commons Attribution International License (CC BY 4.0).

http://creativecommons.org/licenses/by/4.0/

(c) (i) Open Access

\begin{abstract}
Users in social networking sites, such as Facebook, are increasingly receiving friend requests from strangers. This study examines the effects of the Big Five personality traits (Neurotics vs. Extroversion vs. Openness vs. Conscientiousness vs. Agreeableness) and strangers' gender in affecting Facebook users' decisions to accept (or ignore) the stranger's friend request. Results showed that gender of the stranger and the personality match between participant and stranger jointly affect the decision to accept the stranger as friend on Facebook. Most of the participants accepted the stranger's friend request based on textual cues that were displayed in the friend request message. This finding supported Social Information Processing theory, suggesting that impression formation of the stranger was not constrained to the lack of nonverbal cues online. Moreover, participants were more likely to accept the stranger's friend request when the participant's and stranger's personalities matched. This effect was more pronounced when the stranger was a female. Participants accepted female stranger's friend request due to the inflated perception of stereotypical female characteristics, which supports the Hyperpersonal Perspective.
\end{abstract}

\section{Keywords}

Facebook, Big-Five Personality Traits, Stranger, Friend

\section{Introduction}

The Internet is one of the fastest growing technologies that have changed the dynamics of interpersonal communication [1]. Parks and Floyd [2] found that $60.7 \%$ of respondents formed an online personal relationship with individuals whom they have met for the first time in an Internet newsgroup. Social networking sites offer an interactive setting for users to maintain relationships with 
other people [3].

Sophos, an IT security firm, created a fake Facebook user named "Freddi" to test and see how many members would accept this stranger as a friend. "Out of 200 members, 87 accepted 'Freddi' as friends and 82 provided 'Freddi' private information about themselves" ([4], 1). The alarming number of users who accepted "Freddi" into their friends' list seems to contradict the advice that parents provide to children, "Do not talk to strangers!"

What influences users to accept strangers as friends in online social networking sites when they do not even talk to strangers in face-to-face (FtF) situations? Specifically, this study aims to 1) examine the effect of different personalities in strangers on Facebook users' decision to accept the stranger's friend requests and 2) analyze the relationship between personality traits and gender of strangers in affecting Facebook users' choices to accept friend requests from strangers. We first reviewed the literature on factors that influence people's decision to accept stranger as friend on social networking sites, then we conducted an experiment to empirically test the hypotheses. After that, we reported the results and discussed its implication theoretically and practically.

\section{Literature Review}

Online social networking sites allow individuals to connect and communicate with people whom they may or may not know. People can engage in online conversations with other individuals through random chat rooms or by accepting friend requests from other people. Numerous social networks such as Friendster, MySpace, and Multiply have emerged within the last few decades.

\subsection{Facebook: The New Tool}

The most prominent social networking site that has influenced relationship development in the virtual environment is Facebook [3] [5] [6]. The need to connect with others has made Facebook more prevalent in society. Facebook is an online network that allows people to post messages, search for friends, maintain relationships, and provide personal information on users' accounts. Facebook was initially created in 2004 by a student from Harvard University, Mark Zuckerberg [7]. The number of users in Facebook has increased from 21 million in 2007 [8] to 175 million in 2009 [7]. Most users in Facebook are college students [9].

According to Lampe, Ellison, and Steinfield ([10]), Facebook users create profiles and maintain the connection of their social networks through "friend" requests, which can come from friends, acquaintances, or strangers. Accepting strangers into the friends list also allows strangers to gain access into the private information that users display in their account [11]. In Facebook, the availability of users' personal information or photos assist individuals in their search for existing acquaintances or just to bridge weak ties [8], which influences the intensity of using Facebook as a means to connect with other individuals. Lampe et al. 
([10]) stated that Facebook's function of allowing users to search for other people's profiles reduces the costs of connection in that the transaction costs between individuals are not high.

Besides searching for common friends, users may also search for strangers or individuals who appear in their suggested social network. Since CMC is often anonymous, strangers or individuals who appear in users' suggested social networks may be people with fake identities. Baym ([12]) claimed that people create online identities and have the choice of revealing their true or fake identities in virtual settings. For example, Sophos created a fake Facebook user named "Freddi" to solicit other users and found that more people accepted rather than ignored the friend request [4]. However, the experiment did not include personality traits as a possible factor that may have influenced Facebook users' decisions to accept "Freddi" as a friend.

Although Facebook can be a convenient way to connect with other people, it may also bring about harmful consequences if users do not set privacy boundaries in revealing personal information on their profile pages. Researchers [5] [11] [13] in the recent years have focused on the effects of self-disclosure that has affected privacy boundaries among various age groups, specifically among students. When individuals feel that the self-disclosure does not entail a great personal cost or risk, they are more willing to participate [14]. In Facebook, users may perceive the cost or risk of self-disclosure as less serious, as the primary purpose is not to ward off strangers but to share their experiences with other users and connect with friends [5] [13].

The need to create a sense of presence and form identities online has also encouraged people to establish an online "self" to maintain their connection with other users [10], especially in social networking sites that allow users to update or change any amount of private information with no limitations. The virtual environment provides a way to conceal physical imperfections, which allow users to conceal their true identity or appearance and engage in an idealized online "self" through the online medium [15].

\subsection{Social Information Processing Theory and Hyperpersonal Effect on Impression Formation}

When Facebook users receive a friend request, they will typically see the photo image and/or message of the solicitor. The request will also contain functions for users to accept, decline, or send a message to the solicitor. One of the theories that may explain the bizarre notion of accepting strangers' friend requests is Social Information Processing (SIP) theory. Walther $([16], 10)$ proposed that SIP reflects how individuals "form simple impressions through textually conveyed information" in CMC. SIP theory provides a framework that explains how individuals perceive $\mathrm{CMC}$ to be as personal as FtF interactions, if given sufficient time [16] [17].

People adapt to the linguistic codes and use it as a channel to form impres- 
sions of other users through messages that are displayed in their information without the presence of physical nonverbal cues [18] [19] [20]. The absence of physical nonverbal cues such as facial expressions or eye contact may not have an effect in users' decision to decide on friend requests that they receive from either friends or strangers. Although studies [18] [19] [21] have discovered that CMC users are influenced by textual messages with the absence of nonverbal cues, few studies have examined the phenomenon of accepting strangers as friends in social networking sites based on the inadequate textual information that solicitors provide though friend request.

The asynchronous effect of Facebook's friend requests provides sufficient time and linguistic cues for individuals to form impressions of the solicitor. Messages in Facebook's friend requests provide the most salient information where impression is directly derived by users, which affects users' decision to accept or ignore the solicitation. Although text cues travel slower than oral speech in CMC, Walther [16] argued that interpersonal impressions in CMC would eventually be on par with FtF communication because impressions grow gradually over time. Under unique circumstances when the level of affection is parallel with FtF situations, users may even view strangers more positively. Walther [16] coined the term "hyperpersonal effect", which explains the inflated perception and impression that online users form about other people in CMC environments due to lack of nonverbal cues. Online users may exaggerate or inflate their positive impressions of others in CMC settings when they engage in selective impression formation of the other person based on textual cues [22] [23]. Researchers [3] [20] [24] have examined Facebook from various perspectives but neglected to examine effects of strangers' invitations to users' relational development in Facebook. The inflated impression that users perceive while interpreting friend requests may motivate users to accept or ignore strangers as friends based on user's positive or negative impression formation of the stranger.

According to Chester and Bretherton [25], impression management is the process of managing and maintaining self-image before others. Online users engage in impression management through the use of language, pictures, messages received or sent, and nonverbal cues such as emoticons [20] [22] [24] [26]. Friend requests generally come from individuals who are interested in seeking permission from users to add them into users' list of friends or online social network. Senders may manage their self-presentation through a picture and message that is displayed in the friend request. On the other hand, users who receive friend requests engage in impression formation of the solicitor based on the information that is provided by the sender.

Adkins and Brashers [26] found that messages can relay powerful or powerless positions in the CMC environment. Language can depict individuals' self-representation through the use of grammar and spelling in online messages [27]. The text-based solicitations and use of language in messages can significantly affect users to accept strangers' requests to be added into users' friend lists. On the other hand, messages in friend requests that portray negative im- 
pressions may be rejected. Hancock and Dunham [22] noted that the CMC environment can cause individuals to intentionally derive positive text-based cues from messages while paying lesser attention to behavioral cues that are not within their control. Messages can reflect a positive or negative self-presentation of the stranger. Thus, this study will also examine the effects of different messages on users' willingness to accept the stranger's friend request based on the Big Five personality traits.

Most research [3] [11] [13] have focused on a third party or the passive role of Facebook users, such as examining the effects of users' friends on users' online behavior. However, this study will examine users taking on the active role of controlling their self-representations. In this study, Facebook users take on the active role of a stranger who will solicit other users through friend requests. The present study proposed to examine stranger's effect on Facebook users through self-presentations in friend requests. Therefore, the following research questions are proposed:

RQ1: What factors prompt users to accept strangers' friend requests in Facebook?

\subsection{The Big Five Traits in CMC}

McCrae and Costa [28] claimed that the Five-Factor Model (FFM), or what most researchers refer to as the Big Five, provides a comprehensive and manageable guide to study individuals' personalities in different contexts. Personality traits construct people's experiences and thoughts. The FFM captured most personality traits when McCrae and Costa asked individuals "Who am I?" ([28], 58). Through the FFM, Costa and McCrae [28] constructed the NEO Personality Inventory (NEO-PI), which is commonly used by psychologists to distinguish abnormal behaviors or changes in individuals' personality traits. The field of psychology often adopted NEO-PI to assess individuals' personality traits as all NEO inventories assess the Big-Five Factors [29] [30]. The NEO-PI provides several facets to analyze individuals' personality and items include a 5-point Likert scale ranging from strongly disagree to strongly agree [31]. The Big Five's facets that are applicable globally include Neuroticism, Extraversion, Openness, Agreeableness, and Conscientiousness [29].

Throughout the years, researchers [32] [33] [34] [35] have modified the Big-Five Factor structure and used it to examine Internet psychology. The effects of different personality types may influence individuals' decisions to accept solicitors, who may be strangers, as friends in social networking sites. Individuals generally fall into one of the Big Five categories of Neuroticism, Openness, Extraversion, Agreeableness, or Conscientiousness (NEOAC) [36]. Hamburger [37] claimed that different personalities impact users' Internet behaviors. Understanding users' motivations to engage in different online activities can explain the various factors that influence users to accept strangers' friend requests. Therefore, this study proposes the following research question: 
RQ2: How does each personality trait in the Big Five category influence participants' decisions to accept strangers' friend requests in Facebook?

Researchers [38] [39] [40] [41] have examined the relationship between different personality traits among Internet users and their preferences to use the Internet as a means for socializing with others. Most researchers [36] [39] [42] [43] [44] focused on the distinction between the Internet usage of individuals with Neuroticism and Extraversion traits. Individuals who are Neurotic tend to be emotionally unstable, anxious, and insecure [37]. On the other hand, individuals who fall into the category of Extraversion engage in fun or sociable activities [45]. Hamburger, Wainapel, and Fox [46] discovered that individuals who were high in Neuroticism identified with their true self through the Internet whereas individuals who were high in Extraversion related to their "real me" through face-to-face interaction. The Internet can be a tool to escape social discomfort for socially anxious and lonely individuals, which exemplifies the trait of Neuroticism [41]. People perceive individuals who experience loneliness or anxiety as high in Neuroticism because of their need for belonging [37] [47] and general negative bias [42] [43].

Extraversion is a trait that involves positive emotions of enjoying and seeking pleasurable activities [43]. People may perceive others who exemplify more Extraversion traits as individuals who are optimistic or sociable because of their interest in voicing their opinion [37] [48]. Many researchers [23] [36] [42] [43] [46] have placed the focus of examining Neuroticism and Extraversion traits on individuals' preferences in Internet usage but have neglected to examine the perceptions of Facebook users toward strangers with these traits. Since Extraversion and Neuroticism traits have a vast difference in providing other users a positive or negative impression of the individual, friend request messages with Extraversion traits may be more likely to receive acceptance from other users whereas messages that reflect Neuroticism may be more likely to be rejected. Therefore, this study proposes the following hypothesis:

$\mathrm{H1}$ : Participants will accept friend requests from strangers displaying Extraversion traits more than Neuroticism traits.

Individuals who are Agreeable tend to compromise in favor of others to maintain a harmonious relationship [37]. Social network users with high Agreeableness traits exemplify supportive behaviors toward other users compared to individuals with other traits [39] [49]. Although both Extraversion and Agreeableness traits portray positive impressions, strangers with Agreeableness trait may receive more acceptances through friend requests because they have the tendency to comply in order to build social harmony, whereas strangers with Extraversion trait may be less likely to receive acceptance from friend requests because they are more interested in stating their opinion rather than accepting other people's opinion [37]. Therefore, the following hypothesis is proposed:

$\mathrm{H} 2$ : Participants are more likely to accept friend requests from strangers displaying Agreeableness traits than Extraversion traits. 
Individuals who have high levels of Conscientiousness trait tend to be more organized, careful, and disciplined [37] [50]. Landers and Lounsbury [39] found that students who were high in Conscientiousness trait utilized the Internet lesser than students with other traits. On the other hand, individuals with Openness trait were more likely to engage in self-enhancement when maintaining personal images and self-identity claims online [36] [51] [52] [53]. In Facebook, identity claims or personal information in friend requests' messages can affect users' decision to accept the stranger as friends.

Although researchers [36] [39] [49] [53] have studied and bridged the relationship between users' personalities and Internet usage, past research have not clearly distinguished the difference between perceptions of users toward strangers with Openness and Conscientiousness traits in affecting users' decisions to accept or ignore friend requests from strangers with these traits. Strangers with high Openness trait may present an intellectual and individualistic image, which may attract users to accept them as friends whereas strangers with high Conscientiousness trait reflect a rigid self-presentation because of their preference for structure and organization [37], which may influence users to view them as unsociable or inflexible to change. Thus, this study proposes the following hypothesis:

H3: Participants are more likely to accept friend requests from strangers displaying Openness trait than Conscientious trait.

Researchers [38] [42] [43] [54] claimed that gender can be a factor that influences users' preferences in Internet usage and reflection of users' identities. Females are more likely to construct their identities through the influence of other users whereas males are more likely to distinguish their individuality from others [41] [54]. Researchers [42] also noted significant differences between males and females with Neuroticism and Extraversion traits in Internet usage. For men, Extraversion was associated to leisure activities whereas for women, Extraversion was associated to social services. Women who are high in the Neuroticism trait are more likely to maintain blogs compared to women who are low in Neuroticism trait [36]. Gender differences can significantly impact users' decisions to accept or reject friend requests from strangers. Hamburger and Ben-Artzi [42] argued that women are more self-conscious because they are more attentive. Strangers with Neurotic personalities may trigger female online users' emotional aspects terms of accepting the Neurotic stranger as friends compared to male users who may be less attentive. Therefore, this study proposes the following research question and hypothesis:

RQ3: How does the stranger's gender influence participants' decisions to accept the stranger's friend request?

H4: Female participants are more likely to accept friend request from strangers with Neurotic trait than male participants.

\section{Method}

A 2 (gender of the stranger: male vs. female) $\times 5$ (stranger's personality: Neuro- 
ticism vs. Extraversion vs. Openness vs. Conscientiousness vs. Agreeableness) factorial design was conducted to assess the effects of gender and personality traits of the strangers on Facebook users through friend requests.

\subsection{Participants}

Participants $(N=235)$ were recruited from a Southwestern university in exchange for extra credit in communication courses. Participants were required to have a Facebook account that is set up for all users to search and add them as friends. Forty-three percent of the participants were male. The sample of participants consisted of 55\% Caucasian, 18\% African American, 14\% Hispanic, 10\% Asian American, and 3\% from other ethnicities. Participants' ages ranged from 18 to $52(M=20.78, S D=4.01)$.

\subsection{Procedures}

Prior to the study, participants were required to provide the researcher with their email addresses that they used to log into their Facebook accounts. The researcher validated each participant's eligibility to participate in the study by searching for the participants in Facebook through their email addresses. Upon arrival at the computer lab, participants signed in and were given a case ID. The researcher then assigned participants to an available computer station in the lab. After signing informed consent form, participants first answered a 25 -item online personality questionnaire. The researcher sent out "friend" requests while participants were reading the informed consent form and completing the personality questionnaires. Each participant was randomly assigned to receive one of the ten versions of friend request mock-ups from Facebook strangers named Tyler (male) or Nancy (female).

After participants have completed the online personality questionnaire, they were instructed to log onto their Facebook accounts. First, participants were directed to check their wall postings. Then, participants were asked to check for friend requests and respond to the latest friend request from either Tyler or Nancy. Upon completion of the task, participants were asked to complete several online questionnaires about the stranger and provide their demographic information.

\subsection{Stimuli}

Ten sets of Facebook mock-up were included as stimuli for this study. Each version reflected a friend request, which included a photo of the stranger (male or female versions) and a message that portrayed one of the Big Five traits.

Photo of The Stimuli: Since physical attraction was not the focus of this study, the strangers' attractiveness were kept constant and acquired from a photo-rating Website (i.e. hotornot.com). The male and female versions of stimuli presented neutral photo images. The photo-rating website is opened for the public to view photo images of individuals who were rated on a scale of 1 to 10 by 
their social network or users of the website. The photo images that fell between the neutral ratings of 5 or 6 were obtained.

Message: Messages that reflected the Big Five traits were created. The message for Neuroticism trait displayed a desperate individual with mood swings and in need of a friend. The message for Extraversion trait reflected an individual's love for socializing, outdoor activities, and excitement. For the Openness trait, the message depicted a creative individual who loved art and adapted to new situations quickly. The message in Agreeableness trait reflected an individual who loved people for who they were and tried to reciprocate the liking of others to conform. The message for Conscientiousness trait reflected a person who was well-planned, organized, and appreciated structure. Messages for each trait remained the same for both male and female versions of the stimuli.

\subsection{Measures}

Big Five Traits. In this study, participants were asked to rate their personalities based on the 25-items of Big Five traits from the IPIP scale. Cronbach's Alpha for Neuroticism, Extraversion, Agreeableness, and Conscientiousness were $\alpha=$ $0.77, \alpha=0.84, \alpha=0.71$, and $\alpha=0.82$, respectively. The researcher then computed index scores for participants' self-reported personality traits and picked the highest score that each participant belonged in the Big 5 traits as participant's personality trait. Sixteen percent of the participants belonged to Extraversion, $31 \%$ were Openness, $40 \%$ were Agreeableness, and 14\% were Conscientiousness. No participants fell into the category of Neuroticism.

\section{Results}

\subsection{Manipulation Check}

The validity of the stranger's "friend" solicitation that contained the Big Five traits was tested using IPIP scale in a pilot test. Eight two students from two communication classes were given screen shots of the stimuli. Students rated a 25-item scale for one of the ten stimuli that they received. The 5-point Likert scale ranged from 1 (accurate) and 5 (inaccurate) in the IPIP scoring. Each trait consisted of 5 items that described the characteristics of the specific trait.

First, the reliability check was conducted on the 25-items assessing the perception of strangers' messages according to each of the Big Five traits. The scale measuring Neuroticism achieved Cronbach's $\alpha=0.88$, Extraversion achieved $\alpha=$ 0.90 , Openness achieved $\alpha=0.72$, Agreeableness achieved $\alpha=0.86$, and Conscientiousness achieved $\alpha=0.83$. Since all the scales were reliable, the index scores for each trait were computed taking the mean score of the items. Table 1 showed the mean and standard deviation of the students' perceptions of strangers with different traits.

A series of paired sample $t$-tests were conducted to compare the mean differences between the targeted trait of participant's perception of the stranger and the other trait perception of the stranger that scored the closest to the targeted 
Table 1. Mean and standard deviation of participants' perception of stranger's personality trait.

\begin{tabular}{|c|c|c|c|c|c|c|c|c|c|c|c|}
\hline \multirow[t]{2}{*}{ Condition } & \multirow[t]{2}{*}{$\mathrm{N}$} & \multicolumn{2}{|c|}{ Neuroticism } & \multicolumn{2}{|c|}{ Extraversion } & \multicolumn{2}{|c|}{ Openness } & \multicolumn{2}{|c|}{ Agreeableness } & \multicolumn{2}{|c|}{ Conscientiousness } \\
\hline & & M & SD & M & $\mathrm{SD}$ & M & $\mathrm{SD}$ & M & $\mathrm{SD}$ & M & SD \\
\hline Neurotic stranger & 17 & 2.26 & 0.55 & 4.20 & 0.68 & 3.19 & 0.66 & 3.08 & 0.91 & 3.27 & 0.70 \\
\hline Extrovert stranger & 13 & 4.00 & 0.72 & 2.31 & 0.77 & 3.12 & 0.44 & 2.66 & 0.59 & 3.06 & 0.59 \\
\hline Openness stranger & 17 & 3.65 & 0.93 & 3.00 & 1.14 & 2.34 & 0.89 & 2.60 & 1.03 & 2.90 & 0.57 \\
\hline Agreeableness stranger & 16 & 3.41 & 1.04 & 3.11 & 0.96 & 2.94 & 0.50 & 2.21 & 0.65 & 3.00 & 0.56 \\
\hline Conscientiousness stranger & 16 & 3.00 & 0.81 & 3.26 & 0.68 & 3.24 & 0.69 & 3.03 & 0.66 & 2.00 & 0.84 \\
\hline
\end{tabular}

trait. Successful manipulation check showed that students who received the "friend" message from the stranger who displayed Neuroticism trait rated that stranger as significantly lower on Neuroticism than any other trait (since 1 was accurate and 5 was inaccurate in the scale). Students who received the "friend" message from Neurotic stranger, 2.26 was the mean score for their rating of the stranger on Neuroticism, and the other trait that was closest to the mean score of Neuroticism was Agreeableness $(M=3.08, S D=0.91)$. Paired-sample $t$-test showed that this mean difference between these two perceptions was significant $t(16)=-2.91, p=0.01$. This means that participants who received the friend request from Neurotic stranger did perceive that stranger as Neurotic, rather than any other traits. Similarly, for students who received "friend" message from strangers who were Extraverted provided 2.31 as the mean score for their Extraversion perception and Agreeableness was the closest rating to Extraversion ( $M$ $=2.66, S D=0.60)$. Paired sample $t$-test showed that mean difference between perceptions of Extraversion vs. Agreeableness was significant, $t(12)=-2.22, p=$ 0.05. Students who received "friend" message from Openness strangers provided the mean score of 2.34, and Agreeableness was the closest rating to Openness ( $M$ $=2.56, S D=1.03)$. Paired-sample $t$-test showed that the mean difference between these two perceptions was significant, $t(16)=-2.06, p=0.05$. Students who received "friend" message from strangers who were Agreeable provided the mean score of 2.21 for their Agreeableness perception, and Openness was the closest rating to Agreeableness $(M=2.94, S D=0.65)$. Paired sample $t$-test showed that this mean difference between these two perceptions was significant, $t(15)=-3.43, p<0.01$. Students who received "friend" message from strangers with Conscientiousness trait provided the mean score of 2.00, and Neuroticism was the closest rating $(M=3.00, S D=0.81)$. Paired-sample $t$-test showed that these two different perceptions was significant, $t(15)=-3.96, p<0.01$.

\subsection{Hypothesis Testing}

Overall, 70\% participants accepted the stranger's friend request while 30\% ignored the stranger's friend request. Since the dependent variable, participant's response to the friend request (either accept or ignore), was dichotomous, logistic regression was used to test the hypotheses, controlling participants' number 
of friends.

$\mathrm{H} 1$ predicted that participants will accept friend requests from strangers with Extraversion trait more than strangers with Neuroticism trait. Logistic regression showed participants significantly were more likely to accept strangers with Extraversion trait than Neuroticism trait $(p=0.05)$. The odds ratio, $\operatorname{Exp}(\mathrm{B})$, for participants who accepted strangers with Extraversion trait was 0.36. This indicates when the stranger's trait changed from Extraversion to Neuroticism, the estimated odds of accepting the stranger's friend request multiply by 0.36 . Participants were more likely to accept Extravert stranger's friend request than Neurotic stranger. H1 was supported (see Table 2).

$\mathrm{H} 2$ stated that participants are more likely to accept friend requests from strangers with Agreeableness trait than strangers with Extraversion trait. As shown in Table 2, H2 was not supported. Participants did not differ greatly in accepting stranger's friend request who were either Agreeable or Extraverted ( $p$ $=0.80$ ).

$\mathrm{H} 3$ predicted that participants are more likely to accept friend requests from strangers with Openness trait than Conscientious trait. This prediction was not supported. There was no significant difference between participants' likelihood to accept strangers with Openness and Conscientiousness trait $(p=0.65)$.

H4 stated that female participants are more likely to accept friend request from strangers with Neurotic trait than male participants. This prediction was supported as shown in Table 3. The result was significant for female participants' willingness to accept Neurotic strangers' friend requests compared to male participants $(p=0.04)$. The odds ratio for participants' gender is 0.09 . This indicates when participants' gender changed from female to male, the estimated odds of ignoring Neurotic stranger's friend request multiply by 0.09 . Females were more likely to accept Neurotic stranger's friend request compared to males.

Table 2. Logistic regression (Binary) for hypotheses testing.

\begin{tabular}{ccccccc}
\hline Variable (Stranger's trait) & $\boldsymbol{n}$ & B & S.E. & $\operatorname{Sig}(p)$ & $\operatorname{Exp}(\mathrm{B})$ & $\begin{array}{c}\text { Nagelkerke } \mathrm{R} \\
\text { Square }\left(\mathrm{R}^{2}\right)\end{array}$ \\
\hline Extraversion vs. Neuroticism & 90 & -1.02 & 0.53 & $\mathbf{0 . 0 5}$ & 0.36 & 0.07 \\
Extraversion vs. Agreeableness & 89 & -0.12 & 0.46 & 0.80 & 1.13 & 0.02 \\
Openness vs. Conscientiousness & 91 & -0.22 & 0.48 & 0.65 & 1.24 & 0.11 \\
Openness vs. Neuroticism & 91 & -1.01 & 0.52 & $\mathbf{0 . 0 5}$ & 0.36 & 0.09 \\
Extraversion vs. Conscientiousness & 90 & -0.37 & 0.48 & 0.44 & 1.44 & 0.07 \\
\hline
\end{tabular}

Table 3. Logistic regression (Binary) for male and female participants who accepted strangers with neuroticism trait $(\mathrm{N}=91)$.

\begin{tabular}{ccccc}
\hline Variable & B & S.E. & $\operatorname{Sig}(p)$ & $\operatorname{Exp}(\mathrm{B})$ \\
\hline Gender (female vs. male) & -2.40 & 1.15 & 0.04 & 0.09 \\
Constant & -0.85 & 0.49 & 0.08 & 0.43 \\
\hline
\end{tabular}

Note. Nagelkerke R Square, $\mathrm{R}^{2}=0.23$. 
Additional analyses were conducted to test the effects of other traits in affecting participants' likelihood to accept the stranger's friend request. The result was significant in participants' likelihood to accept strangers with Openness than Neuroticism trait $(p=0.05)$. As shown in Table 2, participants were more likely to accept strangers with Openness trait than Neuroticism trait. The odds ratio for stranger with Openness trait is 0.36 . This indicates when stranger's trait changed from Openness to Neuroticism, the estimated odds of accepting the stranger's friend request multiply by 0.36 . Participants were more likely to accept the friend request from strangers with Openness than Neuroticism trait. However, participants' likelihood to accept friend request from strangers with Extraversion vs. Conscientiousness trait was not significant $(p=0.44)$.

In order o explore all possible factors that affected participants' decisions to accept the stranger's friend request, the main effects of the following variables: gender of the stranger, gender of the participant, participant's personality, stranger's personality, whether participant and stranger have a personality match, were entered into logistic regression as independent variables, as well as all the possible interaction effects among those variables. Interaction terms that were not significant were dropped. Results showed the main effect of whether participant's personality matched with the stranger's personality was significant $(p=0.05)$. The odds ratio for participant's personality that matched with the stranger's personality is 0.28 . This indicates that when participants' trait changed from match to not match with the stranger's trait, the estimated odds of accepting the stranger's friend request multiply by 0.28 . That is, the estimated odds of acceptance actually decreased. Participants were more likely to accept the stranger's friend request when their personality matched with the stranger's personality (Table 4).

Results also indicated a significant interaction effect between whether participant and stranger have a personality match and stranger's gender on affecting participant's decision to accept the stranger's friend request when their personalities matched $(p=0.01)$. The odds ratio for personality match and stranger's gender is 9.36. This indicates when participant and stranger had a personality match if stranger's gender changed from male to female. The estimated odds of accepting the friend request multiply by 9.36 . Participants were more likely to accept the stranger's friend request when their personality matched with the stranger's personality and the stranger was a female, compared to when the personality matched and the stranger was a male. These results answered RQ1 which asked what factors prompt users to accept strangers' friend requests in Facebook.

Results showed no significant effect of stranger's Big Five traits in influencing participants' decisions to accept or ignore the stranger's friend request ( $p=$ 0.29). This result answered RQ2, which addressed how each personality trait in the Big Five category influences participants' decisions to accept strangers' friend requests in Facebook. 
Table 4. Logistic regression (Binary) for main effects and interactions $(\mathrm{N}=187)$.

\begin{tabular}{ccccc}
\hline Main Effect & B & S.E. & $\operatorname{Sig}(p)$ & $\operatorname{Exp}(\mathrm{B})$ \\
\hline Stranger's gender & -0.26 & 0.40 & 0.52 & 0.77 \\
Participant-stranger personality match & -1.28 & 0.65 & 0.05 & 0.28 \\
Participant's personality & & & 0.62 & \\
Stranger's personality & & & 0.29 & \\
Participant's gender & -0.70 & 0.37 & 0.06 & 0.50 \\
Number of friends & 0.00 & 0.00 & 0.07 & 1.00 \\
$\begin{array}{c}\text { Interaction effect: personality } \\
\text { match by stranger's gender }\end{array}$ & 2.24 & 0.88 & 0.01 & 9.36 \\
\hline
\end{tabular}

Note. Nagelkerke R Square, $\mathrm{R}^{2}=0.16$.

Research Question 3 explored the effects of stranger's gender in affecting participants' decisions to accept the stranger's friend request. Results (see Table 4) showed no significant effects of stranger's gender in affecting participant's decision to accept the stranger's friend request $(p=0.52)$. Whether the stranger was a male or female did not make a difference on participants' decision to either accept or ignore the friend request.

\section{Discussion}

The focus of this study is to examine the effects of gender and Big Five traits on Facebook users' decisions to accept or decline strangers' friend requests. Results showed that in general, users were more likely to accept rather than ignore the stranger's friend request. Researchers [16] [17] [20] [21] [55] [56] [57] have proposed that the lack of nonverbal cues in CMC causes online users to pursue other means to derive information in virtual settings. Walther et al. [20] stated that lack of nonverbal cues will not be a challenge for users to derive information in CMC because users develop strategies to inquire information about other users through other cues that are available online.

Besides deriving information through other cues that are available online, users engaged in impression formation in order to make decisions in the friend requests. Perceived similarity and attraction can be contributing factors in influencing online users' impression formation of other individuals in CMC [58] [59] [60] [61]. Results also showed that participants were more likely to accept the stranger's friend request because of perceived similarity in terms of their personalities. Jessmer and Anderson [27] claimed that language can also depict user's self-presentation in online messages. The language style that Extravert strangers displayed in the friend request message included words such as "exciting" and "outdoor activities." People are more likely to accept a stranger's friend request when the stranger provides a positive and normal personality that conforms to social norms compared to Neurotic individuals who are on the negative end of the continuum and display emotional disturbances. Moni- 
toring self-presentations in can influence relational development in CMC settings [62]. The stranger's self-presentation through the friend request message influenced participants' decisions in accepting strangers with Extraversion more than Neuroticism trait.

An interesting finding in this study was the interaction effect between gender and the participant-stranger personality match, even after controlling for the number of friends. Participants were more likely to accept female than male stranger's friend request when their personalities matched with the stranger's personality, regardless of the number of friends that participants had in their Facebook contacts. One possible reason may be caused by the idealized and stereotypical perceptions that participants have formed toward female strangers. Users may have been influenced by the hyperpersonal effect or their inflated perception of female stranger's characteristics according to social norms.

\subsection{Theoretical Implications}

Findings in this study were consistent with SIP theory, which posits that online users will adopt other forms of medium to form impressions of others in CMC [57]. According to the results of this study, the text-based friend requests from strangers did not intimidate Facebook users to decline strangers' invitation. Users are generally influenced by online persuasion through text-based messages and they form impressions of others through the textual contents [8] [63]. Users generally relied on textual descriptions and photo of the stranger to make decisions with the absences of nonverbal cues. When textual cues are salient, the lack of nonverbal cues and direct interpersonal interactions did not hinder participants to make a decision to the stranger's friend request.

Impression formation and impression management played a role in affecting participants' responses to the stranger's friend request. In this study, the researcher intentionally created messages that portrayed Neurotic and Extravert strangers to examine the connection between participants' impression formation on the stranger and the likelihood of accepting the stranger's friend request. Participants were more likely to accept strangers with Extraversion trait as friends compared to strangers with Neuroticism traits. Participants responded to the stranger's friend request without knowing if their personalities matched with the stranger's personality. Participants were given ample time to respond to the stranger's friend request, which provided them the opportunity to form impressions based on the selective self-presentation of the stranger through a message and photo. Past research [42] [43] noted that Neurotic individuals provided a negative self-presentation compared to Extravert individuals, which may be the reason that caused participants to ignore strangers with Neurotic traits as friends in Facebook.

Another reason for declining the Neurotic stranger's friend request may be because Neurotic individuals are often associated with loneliness, social anxiety, and lack social networks [42] [43] [46]. In the Neurotic stranger's message, 
terms such as "lonely" and "sorrows" displayed an individual with emotional problems. Thus, Facebook users are less likely to accept a stranger that presents Neuroticism personality trait, which support that language styles and word choice affects an individual's self-representation in CMC [26] [27]. The impression that Facebook users formed toward the Neurotic stranger's message influenced them to decline the stranger's friend request, even though the level of attractiveness of the stranger's photo was rated as neutral.

Online users' perceptions may be more inflated when give sufficient time in CMC [16]. The hyperpersonal effect occurs when users inflate their perceptions of other individuals in CMC with the absence of cues [16] [22]. People perceive women as more attentive and have higher levels of self-consciousness, which also directs females to use the Internet for different reasons and services [42]. Biased perceptions of gender differences (i.e. females are more sensitive, gentle, and accepting of others than males) could be a factor that influenced the hyperpersonal effect on participants in accepting the female stranger's friend request when both the participant's and stranger's personalities matched with one another. Hancock and Dunham [22] claimed that in the hyperpersonal effect, the intensity of participants' exaggerated and stereotypic views increase and "tend to cluster toward the extreme ranges of the Likert scale" ([22], 330). In this study, the female stranger's self-representation was controlled in the friend request message based on characteristics of each Big Five traits and a photo rated neutral in attractiveness. However, participants may have inflated their biased perceptions of female characteristics according to social norms, which motivated them to accept the female stranger as friends when their personalities matched with the stranger's personality compared to male strangers. Thus, gender can be a major factor in affecting the hyperpersonal effect in CMC, especially in the context of strangers soliciting other users through friend requests.

In addition, the asynchronous format of this study may have been another contributing factor that enhanced participant's hyperpersonal effect on female stranger's friend request. When users have more time to contemplate on the stranger's friend request, the impression that they form toward the stranger become more developed [64]. Hancock and Dunham [22] argued that besides the lack of social and nonverbal cues, individuals' cognitive processes also contribute to the hyperpersonal effect in CMC. Participants' impressions of the stranger may have been more inflated since they were not given a time limit to decide on the friend request.

The findings of this study also showed that users were more willing to accept the stranger's friend request when users' personalities matched with the stranger's personality. In this study, the perceived similarity of personalities in CMC may be the reason that attracted participants to accept the stranger's friend request. Individuals tend to find others who are similar with themselves and the absence of cues can increase individuals' perceived similarity of other people to themselves, which creates a bonding effect between the two individuals who may 
not know one another [17] [24] [65]. Participants may have viewed themselves as belonging to the same personality trait category when their traits matched with the stranger's traits, which in return, influenced them to be more accepting towards the stranger. Perceived similarity causes individuals to see others as similar to themselves based on their inflated perspective [56] [66] [67] [68]. The perceived similarity of stranger's personality trait that matched with participant's personality trait influenced higher levels of attraction toward the stranger, as participants may have viewed the stranger as more agreeable to themselves.

The results of this study were consistent with McCarthy's [4] findings on more users who accepted rather than ignored the stranger named 'Freddy' as a friend in Facebook. The issues of privacy management are connected to participants' likelihood to accept rather than decline the friend request from the mock-up strangers in Facebook. In this study, participants accepted the stranger's friend request when they perceived higher levels of similarity (personality traits) with the stranger through messages displayed in the friend requests, regardless of the limited information that was provided in the friend request. Thus, results in this study suggested that participants' level of privacy management decreased when perceived similarity existed. The concept of who can be the user's friend is based on the individual's interpretation [13]. The tendency to accept the stranger's friend request was higher because participants may have perceived the stranger as non-threatening to their privacy. Montoya et al. [67] stated that perceived similarity can lead to cognitive biases. In this case, participants whose personalities matched with the stranger's personalities accepted the stranger's friend request because participants may have viewed the stranger as similar to them and less threatening to their privacy.

\subsection{Future Research}

This study presents several limitations and directions for future research. First, participants were required to be physically present in the computer laboratory to complete the experiment. This artificial lab setting may influence participants' response to the friend request. Future research could assess the likelihood of $\mathrm{Fa}$ cebook users' decisions to accept or ignore strangers' friend requests by sending random friend requests through the social network and allowing participants to respond in their comfort settings.

Second, this study only seeks to examine the effects of stranger's personality trait and gender in affecting Facebook users' decisions to accept or ignore random friend requests. Other factors such as stranger's physical attractiveness, and users' differential inclination level of self-disclosure may have affected their decisions to accept the stranger as a friend. Future research could examine the effects of personality traits on users' privacy management to determine the factors that influence them to self-disclose in social networking sites (i.e. self-disclosing private information by accepting strangers as friends).

Besides self-disclosure and privacy levels, the number of mutual friends may 
be another factor that motivates users to accept strangers as friends. Users' perceptions or interpretations of strangers may differ depending on the mutual network in the stranger's profile. Thus, researchers could also examine the effects of mutual friends on users' decisions to self-disclose through social networking sites.

Lastly, culture shapes participants' perceptions on privacy and impression formation of the stranger. This study was conducted in a Southwestern university, where the sample consisted of college students. Since Facebook is becoming more prevalent across other countries and throughout different age groups, future research could examine the effects of stranger's solicitation in cross-cultural dimensions and on different age groups to determine the influence of culture and age on individuals' perceptions of stranger's solicitation.

\section{Conclusion}

The goal of this study was to examine the effects of personality traits and gender of the stranger on Facebook user's decision to accept or decline the stranger's friend request. We found the gender of the stranger and the personality match between participant and stranger jointly affect the decision to accept the stranger as friend on Facebook. In general, participants were more likely to accept than ignore the stranger's friend request. Participants were more likely to accept the stranger's friend request when participant's personality matched with the stranger's personality. Additionally, participants were also more likely to accept female stranger's friend request when their personalities matched. Strangers with personality traits of Openness, Agreeableness, and Conscientiousness did not have significant effects on participants' decisions to accept the stranger's friend request. Future research should continue to examine other aspects of social networking sites in CMC and further explore the effects of impression formation, as well as privacy management through strangers' solicitations in the online environment.

\section{Conflicts of Interest}

The authors declare no conflicts of interest regarding the publication of this paper.

\section{References}

[1] Flaherty, L.M., Pearce, K.J. and Rubin, R.B. (1998) Internet and Face-to-Face Communication: Not Functional Alternatives. Communication Quarterly, 46, 250-268. https://doi.org/10.1080/01463379809370100

[2] Parks, M.R. and Floyd, K. (1996) Making Friends in Cyberspace. Journal of Communication, 46, 80-97. https://doi.org/10.1111/j.1460-2466.1996.tb01462.x

[3] Walther, J.B., Van Der Heide, B., Kim, S.Y., Westerman, D. and Tong, S.T. (2008) The Role of Friends' Appearance and Behavior on Evaluations of Individuals on Facebook: Are We Known by the Company We Keep? Human Communication Research, 34, 28-49. https://doi.org/10.1111/j.1468-2958.2007.00312.x 
[4] McCarthy, C. (2007) Facebook Users Pretty Willing to Add Strangers as "Friends". CNET News. http://news.cnet.com/8301-10784_3-9759401-7.html

[5] Kolek, E.A. and Saunders, D. (2008) Online Disclosure: An Empirical Examination of Undergraduate Facebook Profiles. NASPA Journal, 45, 1-25.

[6] Tong, S.T., Van Der Heide, B., Langwell, L. and Walther, J.B. (2008) Too Much of a Good Thing? The Relationship between Number of Friends and Interpersonal Impressions on Facebook. Journal of Computer-Mediated-Communication, 13, 531-548. https://doi.org/10.1111/j.1083-6101.2008.00409.x

[7] Facebook Factsheet (2009) http://www.facebook.com/press/info.php?factsheet

[8] Ellison, N.B., Steinfield, C. and Lampe, C. (2007) The Benefits of Facebook “Friends:" Social Capital and College Students' Use of Online Social Network Sites. Journal of Computer-Mediated Communication, 12, 1143-1168. https://doi.org/10.1111/j.1083-6101.2007.00367.x

[9] DiMicco, J.M. and Millen, D.R. (2007) Identity Management: Multiple Presentations of Self in Facebook. Proceedings of the 2007 International ACM Conference on Supporting Group Work, Sanibel Island, Florida, 4-7 November 2007, 383-386.

[10] Lampe, C., Ellison, N. and Steinfield, C. (2007) A Familiar Face(book): Profile Elements as Signals in an Online Social Network. Proceedings of the 2007 Conference on Human Factors in Computing Systems (CHI 2007), San Jose, California, USA, April 28-May 3 2007, 435-444.

[11] Govani, T. and Pashley, H. (2005) Student Awareness of the Privacy Implications When Using Facebook. Unpublished Manuscript, Carnegie Mellon University. http://lorrie.cranor.org/courses/fa05/tubzhlp.pdf

[12] Baym, N.K. (1998) Chapter 2: The Emergence of On-Line Community. In: Jones, S.G., Ed., Cybersociety 2.0, Sage Publications, Thousand Oaks, CA, 35-68. https://doi.org/10.4135/9781452243689.n2

[13] Livingstone, S. (2008) Taking Risky Opportunities in Youthful Content Creation: Teenager's Use of Social Networking Sites for Intimacy, Privacy and Self-Expression. New Media Society, 10, 393-411. https://doi.org/10.1177/1461444808089415

[14] Andrare, E.B., Kaltcheva, V. and Weitz, B. (2002) Self-Disclosure on the Web: The Impact of Privacy Policy, Reward, and Company Reputation. Advances in Consumer Research, 29, 350-353.

[15] Rafaeli, S., Raban, D. and Kalman, Y. (2005) Social Cognition Online. In: Hamburger, Y.A., Ed., The Social Net. Human Behavior in Cyberspace, Oxford University Press, New York, 57-90.

[16] Walther, J.B. (1996) Computer-Mediated Communication: Impersonal, Interpersonal, and Hyperpersonal Interaction. Communication Research, 23, 3-43. https://doi.org/10.1177/009365096023001001

[17] Tanis, M. (2007) Online Social Support Groups. In: Joinson, A.N., McKenna, K.Y.A., Postmes, T. and Reips, U., Eds., The Oxford Handbook of Internet Psychology, Oxford University Press, New York, 139-153.

[18] Fagan, J. C. and Desai, C. M. (2003) Communication Strategies for Instant Messaging and Chat Reference Services. Reference Library, 38, 121-155. https://doi.org/10.1300/J120v38n79_09

[19] Koh, S. (2002) The Real in the Virtual-Speech, Self and Sex in the Realm of Pure Text. Asian Journal of Social Science, 30, 221-238. https://doi.org/10.1163/156853102320405825 
[20] Walther, J. B., Loh, T. and Granka, L. (2005) Let Me Count the Ways: The Interchange of Verbal and Nonverbal Cues in Computer-Mediated and Face-to-Face Affinity. Journal of Language and Social Psychology, 24, 36-65. https://doi.org/10.1177/0261927X04273036

[21] Carter, K.A. (2003) Type Me How You Feel: Quasi-Nonverbal Cues in Computer-Mediated Communication. ETC, 60, 29-39.

[22] Hancock, J.T. and Dunham, P.J. (2001) Impression Formation in the Computer-Mediated Communication Revisited. Communication Research, 28, 325-347. https://doi.org/10.1177/009365001028003004

[23] Barak, A. (2007) Phantom Emotions: Psychological Determinants of Emotional Experiences on the Internet. In: Joinson, A.N., McKenna, K.Y.A., Postmes, T. and Reips, U., Eds., The Oxford Handbook of Internet Psychology, Oxford University Press, New York, 303-330.

[24] Walther, J.B., Slovacek, C.L. and Tidwell, L.C. (2001) Is a Picture Worth a Thousand Words?: Photographic Images in Long-Term and Short-Term Computer-Mediated-Communication. Communication Research, 28, 105-134. https://doi.org/10.1177/009365001028001004

[25] Chester, A. and Bretherton, D. (2007) Impression Management and Identity Online. In: Joinson, A.N., McKenna, K.Y.A., Postmes, T. and Reips, U., Eds., The Oxford Handbook of Internet Psychology, Oxford University Press, New York, 223-236.

[26] Adkins, M. and Brashers, D.E. (1995) The Power of Language in Computer-Mediated Groups. Management Communication Quarterly, 8, 289-322. https://doi.org/10.1177/0893318995008003002

[27] Jessmer, S.L. and Anderson, D. (2001) The Effect of Politeness and Grammar on User Perceptions of Electronic Mail. North American Journal or Psychology, 3, 331-346.

[28] McCrae, R.R. and Costa, P.T. (1996) Toward a New Generation of Personality Theories: Theoretical Contexts for the Five-Factor Model. In: Wiggins, J.S., Ed., The Five-Factor Model of Personality: Theoretical Perspectives, Guilford Press, New York, 51-87.

[29] Costa, P.T. and McCrae, R.R. (2008) The NEO Inventories. In: Archer, R.P. and Smith, S.R., Eds., Personality Assessment, Routledge, New York, 213-245.

[30] Srivastava, S. (2008) Measuring the Big Five Personality Factors. http://www.uoregon.edu/ sanjay/bigfive.html

[31] Costa, P.T. and McCrae, R.R. (1992) Normal Personality Assessment in Clinical Practice: The NEO Personality Inventory. Psychological Assessment, 4, 5-13. https://doi.org/10.1037/1040-3590.4.1.5

[32] Digman, J.M. (1990) Personality Structure: Emergence of the Five-Factor Model. Annual Review Psychology, 41, 417-440. https://doi.org/10.1146/annurev.ps.41.020190.002221

[33] Goldberg, L.R. (1990) An Alternative "Description of Personality": The Big-Five Factor Structure. Journal of Personality and Social Psychology, 59, 1216-1229. https://doi.org/10.1037/0022-3514.59.6.1216

[34] Goldberg, L.R. (1992) The Development of Markers for the Big-Five Factor Structure. Psychological Assessment, 4, 26-42. https://doi.org/10.1037/1040-3590.4.1.26

[35] Mount, M.K. and Barrick, M.R. (1998) Five Reasons Why the "Big Five" Article Has Been Frequently Cited. Personnel Psychology, 51, 849-857. https://doi.org/10.1111/j.1744-6570.1998.tb00743.x 
[36] Guadagno, R.E., Okdie, B.M. and Eno, C.A. (2008) Who Blogs? Personality Predictors of Blogging. Computers in Human Behavior, 24, 1993-2004. https://doi.org/10.1016/j.chb.2007.09.001

[37] Hamburger, Y.A. (2007) Personality, Individual Differences and Internet Use. In: Joinson, A.N., McKenna, K.Y.A., Postmes, T. and Reips, U., Eds., The Oxford Handbook of Internet Psychology, Oxford University Press, New York, 187-203.

[38] Caplan, S.E. (2003) Preference for Online Social Interaction. Communication Research, 30, 625-648. https://doi.org/10.1177/0093650203257842

[39] Landers, R.N. and Lounsbury, J.W. (2006) An Investigation of Big Five and Narrow Personality Traits in Relation to Internet Usage. Computers in Human Behavior, 22, 283-293. https://doi.org/10.1016/j.chb.2004.06.001

[40] McKenna, K.Y. and Bargh, J.A. (2000) Plan 9 from Cyberspace: The Implications of the Internet for Personality and Social Psychology. Personality and Social Psychology Review, 4, 57-75. https://doi.org/10.1207/S15327957PSPR0401_6

[41] Peter, J. and Valkenburg, P.M. (2006) Research Note: Individual Differences in Perceptions of Internet Communication. European Journal of Communication, 21, 213-226. https://doi.org/10.1177/0267323105064046

[42] Hamburger, Y.A. and Ben-Artzi, E. (2000) The Relationship between Extraversion and Neuroticism and the Different Uses of the Internet. Computers in Human Behavior, 16, 441-449. https://doi.org/10.1016/S0747-5632(00)00017-0

[43] Hamburger, Y.A. and Ben-Artzi, E. (2003) Loneliness and Internet Use. Computers in Human Behavior, 19, 71-80. https://doi.org/10.1016/S0747-5632(02)00014-6

[44] Oberlander, J. and Gill, A.J. (2006) Language with Character: A Stratified Corpus Comparison of Individual Differences in E-mail Communication. Discourse Processes, 42, 239-270. https://doi.org/10.1207/s15326950dp4203_1

[45] Hamburger, Y.A., Ed. (2005) The Social Net: Human Behavior in Cyberspace. Oxford University, New York.

[46] Hamburger, Y., Wainapel, G. and Fox, S. (2002) On the Internet No One Knows I'm an Introvert: Extroversion, Neuroticism, and Internet Interaction. Cyber Psychology and Behavior, 5, 125-128. https://doi.org/10.1089/109493102753770507

[47] Witte, S.E., Frank, M.L. and Lester, D. (2007) Shyness, Internet Use, and Personality. Cyber Psychology and Behavior, 10, 713-716.

https://doi.org/10.1089/cpb.2007.9964

[48] Hamburger, Y.A. (2002) Internet and Personality. Computers in Human Behavior, 18, 1-10. https://doi.org/10.1016/S0747-5632(01)00034-6

[49] Swickert, R.J., Hittner, J.B., Harris, J.L. and Herring, J.A. (2002) Relationships among Internet Use, Personality, and Social Support. Computers in Human Behavior, 18, 437-451. https://doi.org/10.1016/S0747-5632(01)00054-1

[50] Korzaan, M.L. and Boswell, K.T. (2008) The Influence of Personality Traits and Information Privacy Concerns on Behavioral Intentions. Journal of Computer Information Systems, 48, 15-24.

[51] Barbaranelli, C. and Caprara, G.V. (2002) Studies of the Big Five Questionnaire. In: Raad, B.D. and Perugini, M., Eds., Big Five Assessment, Hogrefe \& Huber, Kirkland, WA, 109-128.

[52] Gosling, S.D., Gaddis, S. and Vazire, S. (2007) Personality Impressions Based on Facebook Profiles. Paper Presented at the International Conference on Weblogs and Social Media, Boulder, CO. 
http://www.icwsm.org/papers/3--Gosling-Gaddis-Vazire.pdf

[53] Vazire, S. and Gosling, S.D. (2004) E-Perceptions: Personality Impressions Based on Personal Websites. Journal of Personality and Social Psychology, 87, 123-132. https://doi.org/10.1037/0022-3514.87.1.123

[54] Magnuson, M.J. and Dundes, L. (2008) Gender Differences in “Social Portraits" Reflected in MySpace Profiles. Cyber Psychology \& Behavior, 11, 239-241. https://doi.org/10.1089/cpb.2007.0089

[55] Chidambaram, L. (1996) Relational Development in Computer-Supported Groups. MIS Quarterly, 20, 143-165. https://doi.org/10.2307/249476

[56] Levine, D. (2000) What Rocks Your Boat. Cyber Psychology \& Behavior, 3, 565-573. https://doi.org/10.1089/109493100420179

[57] Walther, J.B. (1993) Impression Development in Computer-Mediated Interaction. Western Journal of Communication, 57, 381-398. https://doi.org/10.1080/10570319309374463

[58] Lea, M. and Spears, R. (1995) Love at First Byte? Building Personal Relationships over Computer Networks. In: Wood, J.T. and Duck, S., Eds., Under-Studied Relationships: Off the Beaten Track, Sage, Thousand Oaks, CA, 197-233.

[59] McKenna, K.Y., Green, A.S. and Gleason, M.E. (2002) Relationship Formation on the Internet: What's the Big Attraction? Journal of Social Issues, 58, 9-31. https://doi.org/10.1111/1540-4560.00246

[60] O’Sullivan, P.B. (2000) What You Don't Know Won't Hurt Me: Impression Management Functions of Communication Channels in Relationships. Human Communication Research, 26, 403-431. https://doi.org/10.1111/j.1468-2958.2000.tb00763.x

[61] Turner, J.W., Grube, J.A. and Meyers, J. (2001) Developing an Optimal Match within Online Communities: An Exploration of CMC Support Communities and Traditional Support. Journal of Communication, 51, 231-251. https://doi.org/10.1111/j.1460-2466.2001.tb02879.x

[62] Bortree, D.S. (2005) Presentation of Self on the Web: An Ethnographic Study of Teenage Girls' Weblogs. Education, Communication \& Information, 5, 25-39. https://doi.org/10.1080/14636310500061102

[63] Guadagno, R. and Cialdini, R. (2005) Online Persuasion and Compliance: Social Influence on the Internet and beyond. In: Hamburger, Y.A., Ed., The Social Net. Human Behavior in Cyberspace, Oxford University Press, New York, 91-113.

[64] Walther, J.B., Anderson, J.F. and Park, D.W. (1994) Interpersonal Effects in Computer-Mediated Interaction: A Meta Analysis of Social and Antisocial Communication. Communication Research, 21, 460-487. https://doi.org/10.1177/009365094021004002

[65] Collins, N.L. and Miller, L.C. (1994) Self-Disclosure and Liking: A Meta-Analytic Review. Psychological Bulletin, 116, 457-475. https://doi.org/10.1037/0033-2909.116.3.457

[66] Johnson, C.D. and Gormly, A.V. (1975) Personality, Attraction, and Social Ambiguity. The Journal of Social Psychology, 97, 227-232. https://doi.org/10.1080/00224545.1975.9923342

[67] Montoya, R.M., Horton, R.S. and Kirchner, J. (2008) Is Actual Similarity Necessary for Attraction? A Meta-Analysis of Actual and Perceived Similarity. Journal of Social and Personal Relationships, 25, 889-922. 
https://doi.org/10.1177/0265407508096700

[68] Sassenberg, L. (2002) Common Bond and Common Identity Groups on the Internet: Attachment and Normative Behavior in On-Topic and Off-Topic Chats. Group Dynamics. Theory, Research, and Practice, 6, 27-37.

https://doi.org/10.1037/1089-2699.6.1.27 